\title{
A Large Deletion of Chromosome No. 1 (46,XY,1?-)
}

\author{
DAGFINN AARSKOG
}

\author{
From the University of Bergen, School of Medicine, Department of Paediatrics, Bergen, Norway
}

Until recently, the only congenital condition that was known to be due to an actual loss of chromosome material was XO Turner's syndrome. No case of complete monosomy for an autosome has as yet been reported. However, it is now well established that partial deletion of an autosome is compatible with life. The deletion most frequently encountered involves the short arm of chromosome 5 (Lejeune et al., 1963), and the deletion which is probably next in frequency involves the short arm of chromosome 18 (de Grouchy et al., 1963). Partial monosomy for the long arm of chromosome 18 (de Grouchy et al., 1964), the short arm of chromosome 4 (Wolf et al., 1965), or the long arm of a G group chromosome (Lejeune et al., 1964) have also been reported repeatedly. Isolated case reports of deletions have involved the terminal segment of one arm of chromosome 3 (Patau, Opitz, and Dewey, 1964); part of the long arm of a $D$ chromosome (Lele, Penrose, and Stallard, 1963); and the terminal segment of the long arm of chromosome 4 (Ockey $e t$ al., 1967).

The purpose of the present paper is to report a new deletion involving slightly more than half of one arm of chromosome No. 1. By means of autoradiography, the deleted arm was identified as the arm which terminates DNA replication early in the synthetic period.

\section{Case History}

This boy was the first child of a 27 -year-old mother and a 28-year-old father. There was no family history of congenital malformations, mental retardation, or abortions. The pregnancy had been uneventful and there was no history of viral infection, radiation exposure, or drug ingestion. Labour was spontaneous at term. The birthweight was $3305 \mathrm{~g}$. and the length $51 \mathrm{~cm}$. On the second day of life, he was admitted to the Children's Hospital in Bergen because of feeding difficulties and vomiting.

Clinical examination revealed generalized hypotonicity. The head circumference was $37 \mathrm{~cm}$. There was a pro-

\footnotetext{
Received January 29, 1968.
}

minent occiput and overriding sagittal suture. The $\vec{\circ}$ palpebral fissure had a slight antimongoloid slant. The $\vec{\omega}$ ears were low set and malformed, with absent lobes. The palate was high arched and narrow. The neck, $\overline{\overline{3}}$ chest, and abdomen were normal on inspection. Both 5 th fingers were incurved. There were marked flexion or contractures of $1 \mathrm{st}, 3 \mathrm{rd}$, and 4th fingers of the right hand, and $1 \mathrm{st}, 3 \mathrm{rd}, 4 \mathrm{th}$, and 5 th fingers of the left hand. These $\mathrm{N}$ fingers could not be fully extended. Extension of the $\circ$ right elbow and both ankles was limited. Slight limitation of abduction of both hips was also noted. There were bilateral equinovarus deformities (Fig. 1 and 2). The lungs and cardiovascular systems were clinically unremarkable. There were no palpable abdominal masses or organomegaly. The external genitals appeared normal and both testes were descended.

Other investigations were normal. They included electroencephalogram, urine analysis, haemoglobin, tot: and differential leucocyte counts, blood urea nitroges. serum calcium and phosphorus, blood sugar, electre? phoresis of serum proteins, and blood amino acid chromatography.

The clinical course was characterized by recurrent $\frac{\mathrm{O}}{\mathbb{}}$ respiratory tract infections, failure to thrive, and marked general muscular hypotonia. He never gained head control. At 5 months of age he weighed only $3100 \mathrm{~g}$. (birthweight $3305 \mathrm{~g}$.), and his length was $59.5 \mathrm{~cm}$. $(2 \cdot 5$ centile). The head circumference was $43.2 \mathrm{~cm}$. (75 centile). The infant's general condition deteriorated and he died at 5 months.

Necropsy revealed no gross abnormalities of the organ systems. The brain appeared normal both on the surface and on cross-section. On microscopical examination, myelination appeared normal, and heterotopic collections of nerve cells or dysplastic tissue were not seen.

Cytogenetic Investigation. Microblood cultures were set up by adding 3 drops of blood to $7 \mathrm{ml}$. tissue culture medium made up of $6 \mathrm{ml}$. Difco T. C. 199 medium and $1 \mathrm{ml}$. human $\mathrm{AB}$ serum. $0.1 \mathrm{ml}$. phytohaemagglutinin (Burroughs Wellcome) was added, and the cultures were incubated at $37^{\circ} \mathrm{C}$. for 3 days. The cultures were labelled by adding $2 \mu \mathrm{Ci}$ of tritiated thymidine (Radiochemical Centre, Amersham, specific activity $5 \mathrm{Ci} / \mathrm{mM}) 5$ hours before termination and treated with desacetyl-methyl-colchicine (Colcemid, CIBA) for the last $1 \frac{1}{2}$ hours of culture. Well-spread metaphases were photographed and their position on the 


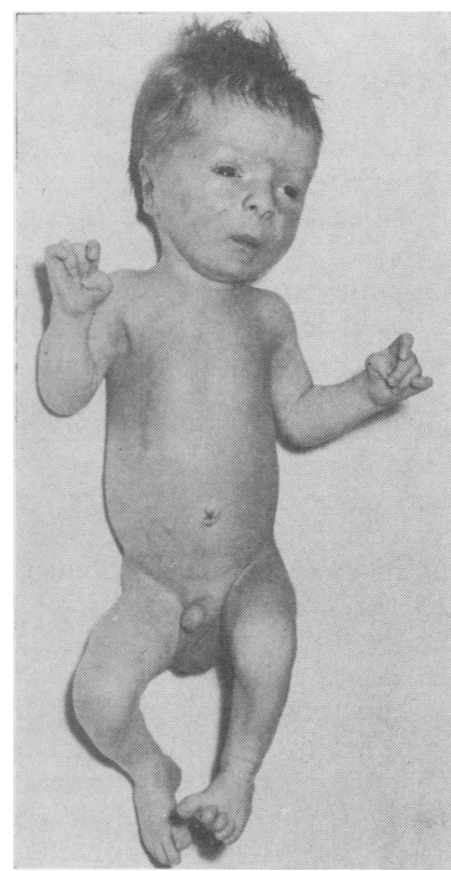

Fig. 1. The patient at 3 weeks of age.

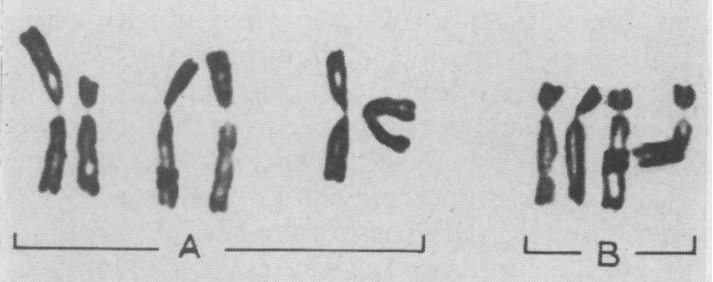

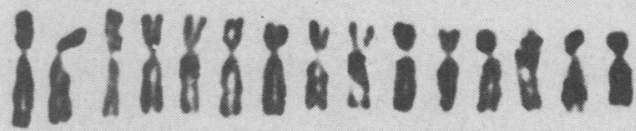

$$
C+X
$$

\section{idodicá}

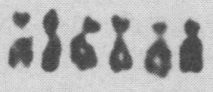

$\longrightarrow$ D
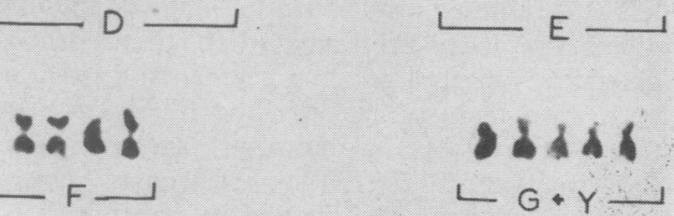

FIG. 3. Karyotype: note deleted chromosome No. 1.

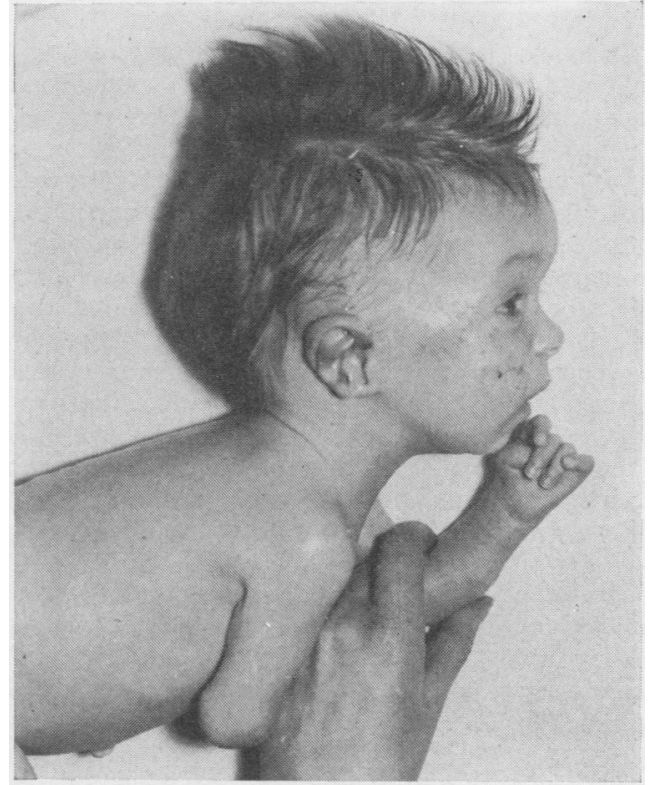

FIG. 2. The facies at 10 weeks of age.

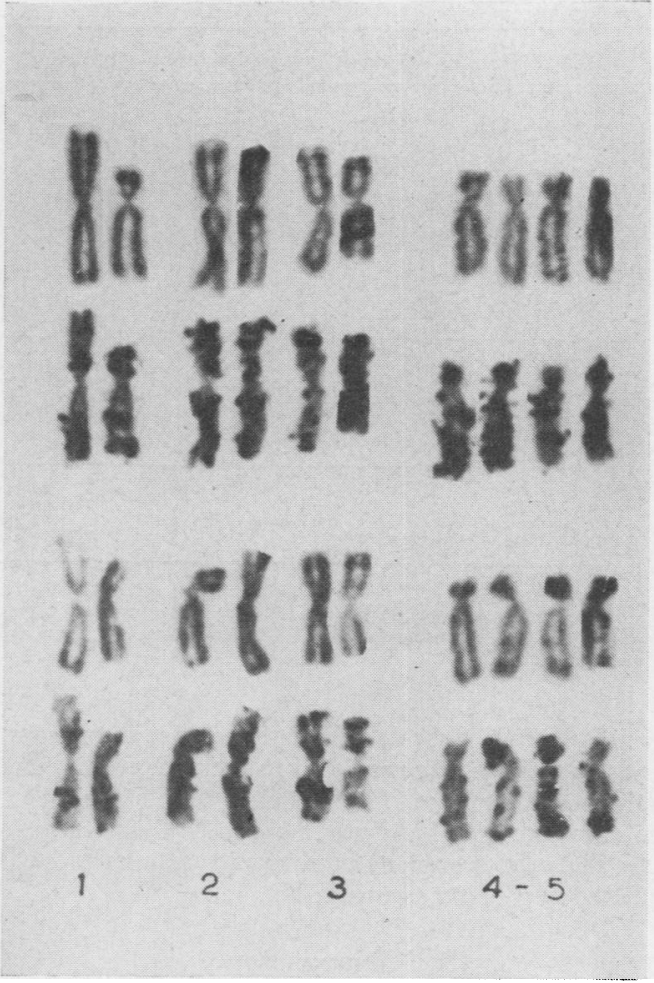

Fig. 4. The largest chromosomes from two cells. The auto radiographs are placed underneath to illustrate the labelling pattern at the end of DNA synthesis. 
slide was recorded. Autoradiographs were then prepared using a stripping film technique.

Chromosomal analysis was carried out on two different occasions. A total of 96 cells was counted and the modal number of chromosomes was 46 . Twenty-six of the metaphases were examined in detail: in each instance the karyotype contained only one chromosome No. 1 and five chromosomes in the B group. On the basis of morphological criteria, the extra chromosome in the B group was selected to be a chromosome No. 1, with a deletion involving slightly more than half of one arm (Fig. 3). On autoradiographs, this chromosome showed a labelling pattern distinctly different from those selected as pairs No. 4 and 5 . The label pattern and grain density of the deleted chromosome resembled that of the normal No. 1, if one assumed a deletion involving the arm with an unlabelled terminal portion (Fig. 4).

Both parents of the patient had normal karyotypes.

Genetic Markers. Genetic marker systems are depicted in the Table. Owing to proven heterozygosity in the patient, the gene loci of the $\mathrm{Gm}, \mathrm{Hp}$, and $\mathrm{Rh}$ systems can be excluded from the deleted part of chromosome No. 1. The same applies most likely to the Pi

TABLE

RESULTS OF BLOOD, SERUM, AND ENZYME TYPING

\begin{tabular}{|c|c|c|c|}
\hline Marker System & Patient & Father & Mother \\
\hline $\begin{array}{c}\text { ABO } \\
\text { MNSsTm } \\
\text { P }_{1} \\
\text { Rh } \\
\text { Le(a) } \\
\text { Lu(a) } \\
\text { K } \\
\text { Fy(a) } \\
\text { Fy(b) } \\
\text { Jk(a) } \\
\text { Jk(b) }\end{array}$ & $\begin{array}{c}\mathrm{O} \\
\text { NsTm- } \\
- \\
\mathbf{R}_{2} \mathbf{r} \\
= \\
= \\
+ \\
+ \\
+ \\
-\end{array}$ & $\begin{array}{c}\mathbf{A}_{1} \\
\text { NsTm }+ \\
- \\
\mathbf{R}_{\mathbf{1}} \mathbf{R}_{2} \\
+ \\
= \\
\overline{+} \\
+ \\
+ \\
+\end{array}$ & $\begin{array}{c}\mathrm{A}_{1} \\
\text { NsTm }^{-} \\
+ \\
\mathbf{R}_{1} \mathbf{r} \\
= \\
= \\
+ \\
\overline{+} \\
+ \\
+\end{array}$ \\
\hline $\begin{array}{c}\mathrm{Gm} \\
\mathrm{Hp} \\
\mathrm{Lp}(\mathrm{a}) \\
\mathrm{Ld}(\mathrm{a}) \\
\mathrm{Gc}\end{array}$ & $\begin{array}{c}1,-2,5,21 \\
2 \cdot 1 \\
- \\
1 \cdot 1\end{array}$ & $\begin{array}{c}1,-2,5,21 \\
2 \cdot 1 \\
+ \\
+ \\
1 \cdot 1\end{array}$ & $\begin{array}{c}-1,-2,5,-21 \\
1 \cdot 1 \\
+ \\
+ \\
1 \cdot 1\end{array}$ \\
\hline$\underset{\mathrm{Pi}}{\mathrm{PGM}}$ & $\begin{array}{c}1 \\
1 \\
M M\end{array}$ & $\begin{array}{c}1 \\
1 \\
M M\end{array}$ & $\begin{array}{c}1 \\
1 \\
M M\end{array}$ \\
\hline
\end{tabular}

Rh, rhesus; Le(a), Lewis; Lu(a), Lutheran; K, Kell; Fy(a)(b), Duffy; Jk(a)(b), Kidd; Hp, haptoglobins; PGM, phosphoglucomutase; AK, adenylate kinase; Pi, protease inhibitor.

and Gc loci since the determinations are semiquantitative, and the results of the analyses in both the patient and his parents all appeared like ordinary $\mathrm{Pi}^{\mathrm{M}} \mathrm{Pi}^{\mathrm{M}}$ and $\mathrm{Gc}^{1} \mathrm{Gc}^{1}$ homozygotes. There was no positive indication that any locus of tested markers could be situated on the deleted part of chromosome No. 1 .

\section{Discussion}

Since chromosome No. 1 is mediocentric it is not possible to distinguish between the two arms on the basis of morphological criteria. However, the $\stackrel{\Phi}{\stackrel{\Omega}{\Omega}}$

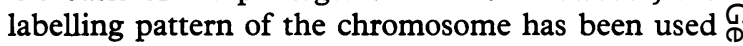
in identification of the two arms, and one arm con- $\overparen{\mathbb{Q}}$ tains a distal segment which terminates DNA synthesis earlier than the remainder of the chromo- os some, and it seems that in the present instance at large part of this distal early replicating region is missing.

Though a number of different autosomal dele- $\widetilde{\Phi}_{\overparen{O}}$ tions have been described, the only firmly established clinical syndrome to emerge is cri-du-chat. The cytogenetic basis for this syndrome is a deletion. of the short arm of chromosome 5. Clinically the $\vec{\omega}$ syndrome is characterized by mental retardation o and certain congenital abnormalities, including a strange cry reminiscent of the cry of a cat. In ir addition to cri-du-chat, it is possible that a partial $\rightarrow$ deletion of the long arm of chromosome 18 is $\underset{N}{\omega}$ associated with a clinically recognizable syndrome $N$ (de Grouchy et al., 1964; Insley, 1967). There are also some indications that deletion of the long arm of a G group chromosome might be associated with $\mathbb{D}$ an antimongoloid condition (Lejeune et al., 1964; Reisman et al., 1966). The clinical findings in cases with deletion of the short arm of chromosome $\stackrel{\mathbb{C}}{-}$ 18 (de Grouchy et al., 1963; Migeon, 1966), or the $\vec{\bullet}$ short arm of chromosome 4 (Wolf et al., 196\% Ockey et al., 1967) have been more heterogeneous and do not allow the delineation of any clinicos: cytogenetic syndrome. The other types of deletions have so far only been reported in isolated cases, and it therefore remains to be seen whether or not they might be associated with definite clinical syndromes. Deletion of chromosome No. 1 of the type described in the present paper has, to the best of the author's knowledge, not been reported before. However, a ring- 1 chromosome has been reported in one instance (Gordon and Cooke, 1964). Ring chromosomes are formed when terminal deletions are fol- $\dot{0}$ lowed by the joining together of the exposed ends. The reported patient was a 5-year-old girl with $\delta$ microcephaly and dwarfism. No other congenital abnormalities were noted.

The recent findings of a relatively wide spectrum of autosomal deletions have been rather unexpected since it was previously assumed that sizeable autosomal deletions of human chromosomes would be lethal. In an attempt to explain the viability of the phenotype, it has been pointed out that most of the $\mathrm{N}$ deletions reported involve segments containing a high proportion of late-labelling DNA and, there- 0 fore, presumably genetically inactive material (Ockey et al., 1967). This explanation, however, $\stackrel{?}{?}$ does not apply to the present case in which there was a relatively large loss of early-labelling DNA, 
and yet only relatively mild phenotypic manifestations resulted.

The accumulated data from reported instances of chromosomal deletions suggest that there is no definite relation between the severity of congenital abnormalities and the quantity of genetic material lost in the deletion. It is also apparent that there are wide variations in the clinical manifestations associated with a presumably similar deletion. Many of these phenotypic manifestations are shared in common by different types of deletions and also by various trisomies. Conceivably, these abnormalities might be related to gross inbalance in genetic material, however caused, rather than to the specific chromosome involved.

\section{Summary}

A boy with multiple minor malformations is described. The clinical course was characterized by developmental retardation, severe hypotonia, recurrent infections, and failure to thrive. The child died at the age of 5 months. Morphological and autoradiographical chromosomal analysis revealed a large deletion of chromosome No. 1 involving the arm containing an early-labelling terminal portion. The gene loci of $\mathrm{Gm}, \mathrm{Hp}, \mathrm{Rh}$, and, most likely $\mathrm{Pi}$ and $\mathrm{Gc}$, can be excluded from the deleted part of the chromosome.

The author wishes to acknowledge the valuable technical assistance of Mrs. Randi Nyquist and Miss Anne Marit Thorbjernsen. Thanks are also due to Dr. T. Gedde-Dahl Jr., Sidsel K. Gundersen, and Brita Merton, University Institute of Medical Genetics,
Oslo, for blood group, Gm, and AK testing; to Drs. $M$. K. Fagerhol and Else Vogt, Blood Group Reference Laboratory, National Institute of Public Health, Oslo, for results on the Pi, Jk, Fy, and Lu systems; and to Drs. E. Fleischer, E. Mohn, and T. Reinskou, University Institute of Forensic Medicine, Oslo, for the Hp, PGM, and $\mathrm{Gc}$ results.

\section{REFERENCES}

Gordon, R. R., and Cooke, P. (1964). Ring-1 chromosome and microcephalic dwarfism. Lancet, 2, 1212.

de Grouchy, J., Lamy, M., Thieffry, S., Arthuis, M., and Salmon, C. (1963). Dysmorphie complexe avec oligophrénie; délétion des bras courts d'un chromosome 17-18. C. R. Acad. Sci. (Paris), 256, 1028.

-, Royer, P., Salmon, C., and Lamy, M. (1964). Délétion partielle des bras longs du chromosome 18. Path. et Biol., 12, 579.

Insley, J. (1967). Syndrome associated with a deficiency of part of the long arm of chromosome No. 18. Arch. Dis. Childh., 42, 140.

Lejeune, J., Berger, R., Réthoré, M. O., Archambault, L., Jérôme, H., Thieffry, S., Aicardi, J., Broyer, M., Lafourcade, J., Cruveiller, J., and Turpin, R. (1964). Monosomie partielle pour un petit acrocentrique. C. R. Acad. Sci. (Paris), 259, 4187.

, Lafourcade, J., Berger, R., Vialatte, J., Boeswillwald, M., Seringe, P., and Turpin, R. (1963). Trois cas de délétion partielle du bras court d'un chromosome 5. ibid., 257, 3098.

Lele, K. P., Penrose, L. S., and Stallard, H. B. (1963). Chromosome deletion in a case of retinoblastoma. Ann. hum. Genet., 27, 171.

Migeon, B. R. (1966). Short arm deletions in group E and chromosomal 'deletion' syndromes. F. Pediat., 69, 432.

Ockey, C. H., Feldman, G. V., Macaulay, M. E., and Delaney, M. J. (1967). A large deletion of the long arm of chromosome No. 4 in a child with limb abnormalities. Arch. Dis. Childh., 42, 428.

Patau, K., Opitz, J. M., and Dewey, W. J. (1964). A multiple congenital anomaly in man presumably caused by a minute deletion in chromosome 3. Science, 146, 429.

Reisman, L. E., Kasahara, S., Chung, C.-Y., Darnell, A., and Hall, B. (1966). Anti-mongolism; studies in an infant with a partial monosomy of the 21 chromosome. Lancet, $1,394$.

Wolf, W., Reinwein, H., Porch, R., Schrøter, R., and Baitsch, H. (1965). Defizienz an den kurzen Armen eines chromosomes Nr. 4. Humangenetik., 1, 397. 